\title{
Clarifying the disagreements on various reuse options: Repair, recondition, refurbish and remanufacture
}

Waste Management \& Research

$1-11$

(c) The Author(s) 2016

Reprints and permissions:

sagepub.co.uk/journalsPermissions.nav DOI: $10.1177 / 0734242 \times 16628981$

wmr.sagepub.com

(SSAGE

\section{Mangesh Gharfalkar ${ }^{1}$, Zulfiqur Ali $^{2}$ and Graham Hillier ${ }^{1,3}$}

\begin{abstract}
Earth's natural resources are finite. To be environmentally sustainable, it may not only be necessary to use them 'efficiently' but also 'effectively'. While we consider 'repair', 'recondition', 'refurbish' and 'remanufacture' to be 'reuse' options, not all researchers agree. Also, there is lack of clarity between the different options that are likely to be challenging for both; the policy makers who formulate policies aimed to encourage 'reuse' of 'waste' products and for decision makers to initiate appropriate action for recovering 'reusable resources' from 'waste streams'. This dichotomy could result into more 'waste' to landfill. A systematic analysis of peer reviewed literature is conducted to understand inconsistencies and/or lack of clarity exist between the definitions or descriptions of identified 'reuse' options. The analysis confirms inconsistencies, such as lack of clarity between options (59\%) and the omission of one or more of identified options from 'reuse' (23\%). This article proposes a 'hierarchy of reuse options' that plots the relative positions of identified 'reuse' options vis-à-vis five variables, namely work content, energy requirement, cost, performance and warranty. Recommendations are made on how to incentivise original equipment manufacturers to 'remanufacture'. Finally, an alternative 'Type II Resource Effective Close-loop Model' is suggested and a conceptual 'Type II/2 Model of Resource Flows' that is restricted to the use of environmentally benign and renewable resources is introduced. These suggestions are likely to help decision makers to prioritise between 'reuse' options, drive resource effectiveness and also environmental sustainability. [AQ: 1]
\end{abstract}

\section{Keywords}

End-of-life, waste, reuse, repair, recondition, refurbish, remanufacture

\section{Introduction}

Considerable research has been done on 'reduce-reuse-recycle' of waste products, but the lack of clarity and inconsistencies between the definitions and/or descriptions of the various 'reuse' options indicates the need for a systematic literature review on this subject. While Gharfalkar et al. (2015) consider 'repair', 'recondition', 'refurbish' and 'remanufacture' to be 'reuse' options, in a majority of cases, 'remanufacturing' is shown distinct from 'reuse', when logically it is part of 'reuse'.

This article is based on the hypothesis of the '5Rs of Resource Effectiveness' (Figure 1) that identifies 'repair', 'recondition', 'refurbish' and 'remanufacture' as different 'reuse' options. The logic is that any measure or an operation that results in 'reuse' of 'waste' objects, either in part or in full, needs to be considered as a 'reuse' option. Also, these options lead to 'reuse' and therefore, conversion of a 'waste' into a 'non-waste'. The European waste directive 2008/98/EC, defines 'waste' as 'any substance or object which the holder discards or intends to discard or is required to discard' (Directive, 2008). Establishing a universally acceptable definition of 'waste' has been a long debated issue in the field of waste regulation, both in the case of European Waste Framework Directives as observed by (Tromans, 2001); and in the case of the Resource Conservation and Recovery Act of the United States as observed by Gaba (1989). Identifying and defining the various stages of 'waste' is also an unresolved issue (Butti, 2012). The importance of 'waste as resource' has been promoted by contemporary ideas, such as 'closed loop' or 'circular economies', that reinforces the notion of a 'resource based' paradigm instead of a 'waste based' paradigm (Park and Chertow, 2014). Moreover, the environmental and economic opportunities offered by the use of carbon containing 'waste' as a 'resource' are substantial ( House of Lords, 2014). In spite of the immense possibilities of using 'waste' as a 'resource', one of the main challenges in achieving such a shift in paradigm is not only in deciding when a 'waste' comes into being, as observed by Butti (2012), but also when it can be 'recovered' and treated as a 'resource'. The authors of this

${ }^{1}$ Centre for Resource Efficient Manufacturing Systems, Teesside University, Middlesbrough, UK

${ }^{2}$ Graduate Research School, Teesside University, Middlesbrough, UK ${ }^{3}$ Centre for Process Innovation, Wilton Centre, Redcar, UK

Corresponding author:

Mangesh Gharfalkar, Centre for Resource Efficient Manufacturing Systems, Teesside University, Phoenix Building, Middlesbrough TS1 3BA, UK.

Email: m.gharfalkaratees.ac.uk 


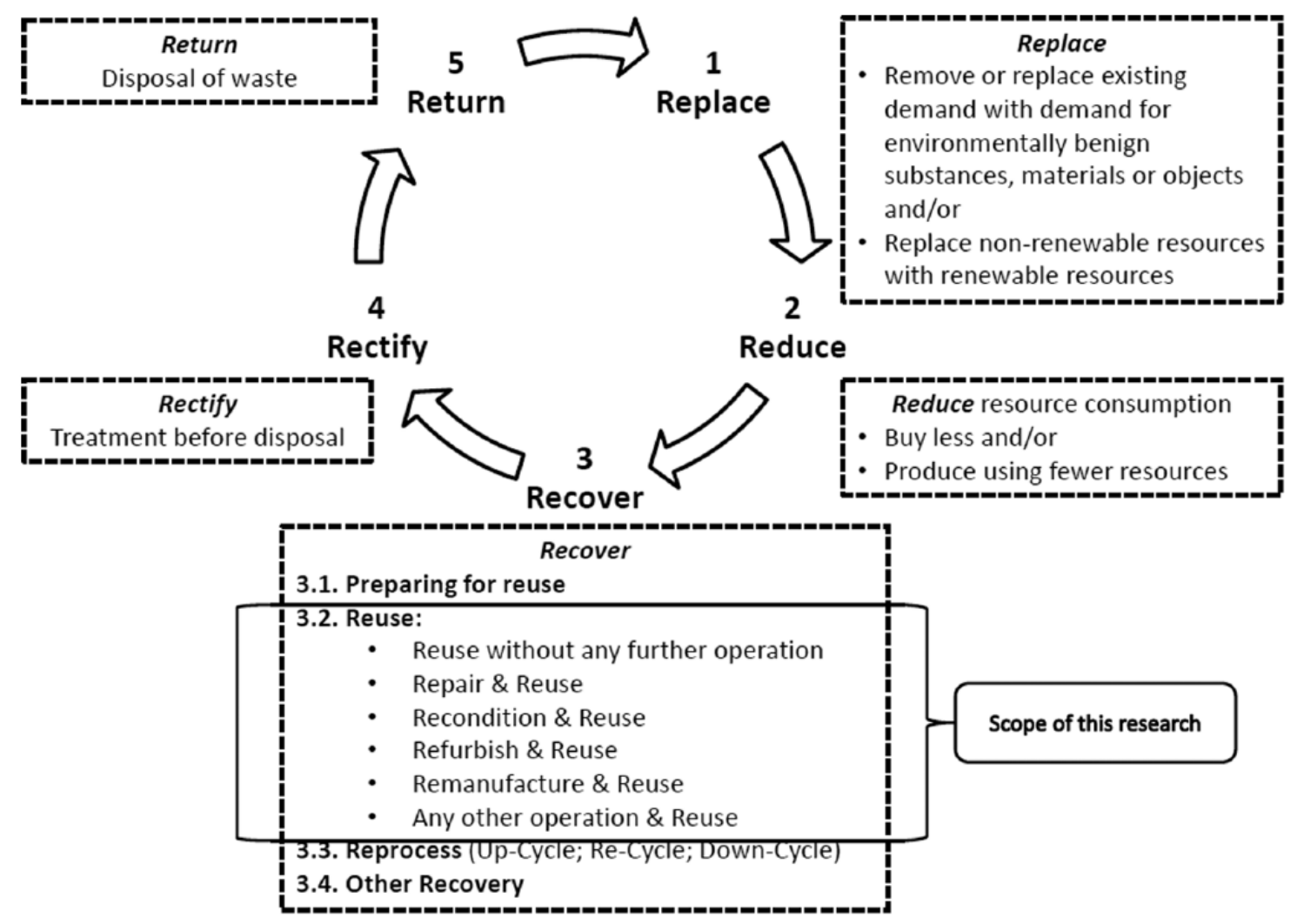

Figure 1. 5Rs of Resource Effectiveness (by Gharfalkar et al., 2015).

article are of the opinion that if the waste categories (in this case, various reuse options) and their definitions are standardised and universally acceptable, then it is likely that the valuable 'resources' contained in the waste could be recovered more effectively.

The Remanufacturing Institute indicates that many terms, such as 'used', 'repaired', 'restored/reconditioned' and 'recycled' are often confused with 'remanufacturing' (The Remanufacturing Institute, 2014). Ziout et al. (2014) identifies 'resale', 'maintenance', 'repair', 'replacement', 'refurbishing' and 'remanufacturing' as some of the other 'reuse' options, but concludes that clear cut definitions and distinctions between these options do not exist in literature or practice. A few examples (anecdotal evidence) of inconsistencies observed in the definitions and/or descriptions of the identified 'reuse' options are described below. These examples capture the inconsistencies, such as exclusion of some of the identified measures or operations or options from 'reuse', lack of clarity in the understanding and the nature of 'remanufacturing'.

1. The six Rs of 'reduce, reuse, recycle, redesign, recover and remanufacture' identified by Gaussin et al. (2013) clearly indicate that 'remanufacture' is distinct from 'reuse'.

2. Seitz and Wells (2006) describe the outcome of a product take-back using reverse logistics as returned products are recovered through different options, such as 'recycling', 'reuse', 'remanufacturing' and 'cannibalisation'. This clearly separates 'remanufacturing' from 'reuse'.
3. Seitz and Wells (2006) observe that 'remanufacturing' transforms worn-out goods into products with an 'as good as new' condition. This is substantiated by an example of 'remanufacturing' of car engines by grinding, machining and abrading of individual parts, such as the cylinder block or cylinder head. Emphasis is laid on retaining the morphology of individual parts. The lack of clarity that exists on 'remanufacturing' is evident from the mention of 'European remanufacturing workshops'. Workshops are not equipped to 'remanufacture', but to 'repair' or 'recondition' or 'refurbish' and 'rebuild' a product. Moreover, owing to intellectual property rights, not all workshops have access to OEM [AQ: 2]specifications and are therefore unable to offer OEM warranties and/or 'as new product', a pre-requisite of a 'remanufactured' product.

This research conducts a literature review to understand whether any inconsistencies and/or overlaps exist between the definitions and or descriptions of various 'reuse' options.

\section{Materials and methods}

Based on the hypothesis that 'repair', 'recondition', 'refurbish' and 'remanufacture' are one group of the many 'reuse' options, this article conducts analysis of literature to highlight the lack of agreement and inconsistencies that exist between these 'reuse' options. The literature search was conducted by identifying peer reviewed articles published in the English language using the 'Discovery' database search engine. This database consists of 


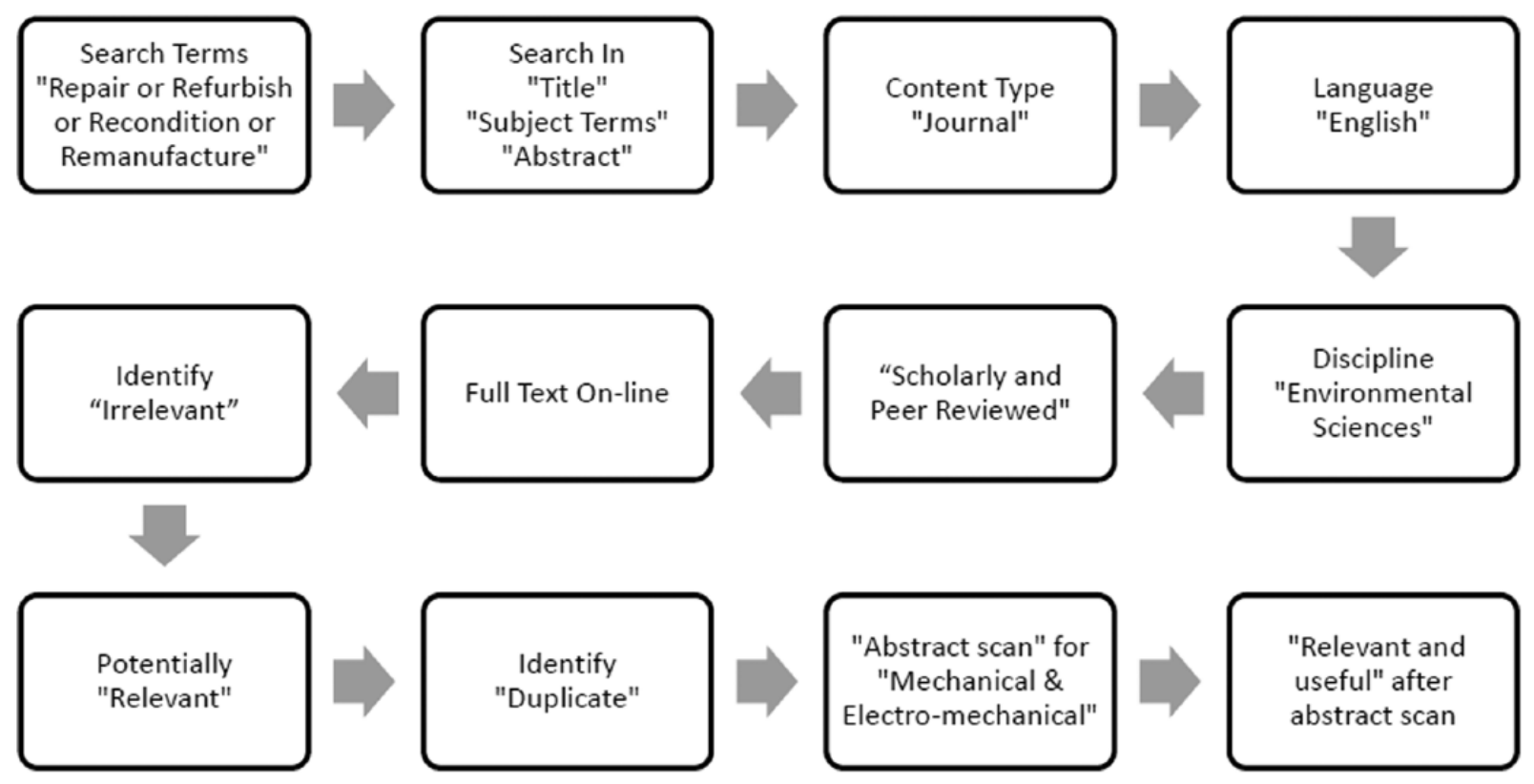

Figure 2. Flowchart for selection of journal articles.

Table 1. Summary of database search.

\begin{tabular}{|c|c|c|c|c|}
\hline Description & 'Title' search & 'Keyword’ search & 'Abstract' search & Total articles \\
\hline Total articles from all disciplines & 144,199 & 181,094 & 294,665 & \\
\hline Articles from environmental science & 384 & 1683 & 1962 & \\
\hline Scholarly and peer reviewed articles & 353 & 1566 & 1868 & \\
\hline Articles with full text online & 140 & 614 & 860 & \\
\hline Irrelevant articles & 125 & 598 & 833 & \\
\hline Potentially relevant articles & 15 & 16 & 27 & 58 \\
\hline Duplicate articles & & & & 18 \\
\hline Potentially useful before abstract scan & & & & 40 \\
\hline Identified as useful after abstract scan & & & & 17 \\
\hline
\end{tabular}

literature published in 170 databases, including Business Source Complete, Emerald Insight, SAGE Journals, Scopus, Science Direct and others. Titles, subject terms (keywords) and abstracts of literature in these databases were Boolean searched using the search phrase 'repair or refurbish or recondition or remanufacture', for the period beginning 1987 to 2015 . The publication of the Brundtland Commission report in 1987 made 'sustainable development' prominent for the first time. This is the reason for setting the cut-off year for literature search as 1987 . Overall criteria for selection of relevant literature are described below. The literature identification and selection process is illustrated in Figure 2. The number of useful articles that were identified through this process are summarised in Table 1.

1. Articles published in English language between January 1987 to April 2015.

2. Articles restricted to environmental sciences discipline.

3. Articles restricted to mechanical and electromechanical products.

4. Articles published in a peer reviewed journal.
5. Full text of the articles available online.

6. No cross references were considered.

The 17 peer reviewed articles identified as useful (Table 1) were analysed using the two simple criteria described below. The outcome is discussed in the next section.

1. Are there any disagreements and/or inconsistencies between the descriptions and/or definitions of identified reuse options, such as repair, recondition, refurbish and remanufacture, in the targeted literature?

2. Does the definition and/or description of 'repair', 'recondition', 'refurbish' and/or 'remanufacture' in the identified literature consider it to be as one of the many 'reuse' options?

\section{Results}

Table 2 and Figure 3 summarises the outcome of the analysis of the 17 articles that were identified as 'useful' within the 'environmental science' discipline for 'mechanical and electromechanical 
Table 2. Results as per criteria. (a) Inclusion or exclusion from reuse and (b) lack of clarity.

\begin{tabular}{|c|c|c|c|c|c|}
\hline Reference & $\mathrm{R} 1$ in $\mathrm{RU}$ ? & $\mathrm{R} 2$ in $\mathrm{RU}$ ? & $\mathrm{R} 3$ in $\mathrm{RU} ?$ & $\mathrm{R} 4$ in $\mathrm{RU}$ ? & $\begin{array}{l}\text { Lack of clarity } \\
\text { or overlap? }\end{array}$ \\
\hline $\begin{array}{l}\text { A holistic approach for decision on selection of end-of-life } \\
\text { products recovery options (Ziout et al., 2014). }\end{array}$ & Y & N.D & Y & $Y$ & Y \\
\hline $\begin{array}{l}\text { A network model to assist 'design for remanufacture' } \\
\text { integration into the design process (Hatcher et al., 2014). }\end{array}$ & Y & $Y$ & N.D & $Y$ & $\mathrm{~N} / \mathrm{A}$ \\
\hline $\begin{array}{l}\text { A review on remanufacture of dies and moulds (Chen } \\
\text { et al., 2014). }\end{array}$ & $\mathrm{N}$ & $\mathrm{N}$ & $\mathrm{N}$ & $\mathrm{N}$ & Y \\
\hline $\begin{array}{l}\text { A tool to implement sustainable end-of-life strategies in } \\
\text { the product development phase (Gehin et al., 2008). }\end{array}$ & $\mathrm{N}$ & N.D & $\mathrm{N}$ & $\mathrm{N}$ & Y \\
\hline $\begin{array}{l}\text { Design for remanufacture: A literature review and future } \\
\text { research needs (Hatcher et al., 2011). }\end{array}$ & N.D & N.D & N.D & Y & N/A \\
\hline $\begin{array}{l}\text { Disassemblability of end-of-life vehicle: A critical review } \\
\text { of evaluation methods (Go et al., 2011). }\end{array}$ & N.D & N.D & N.D & $\mathrm{N}$ & Y \\
\hline $\begin{array}{l}\text { Eco-design methods focused on remanufacturing } \\
\text { (Pigosso et al., 2010). }\end{array}$ & $\mathrm{N}$ & $\mathrm{N}$ & $\mathrm{N}$ & $\mathrm{N}$ & Y \\
\hline $\begin{array}{l}\text { Incorporating component reuse, remanufacture, and } \\
\text { recycle into product portfolio design (Mangun and } \\
\text { Thurston 2002). }\end{array}$ & Y & N.D & N.D & $\mathrm{N}$ & Y \\
\hline $\begin{array}{l}\text { Initiating automotive component reuse in Malaysia } \\
\text { (Amelia et al., 2009). }\end{array}$ & N.D & N.D & N.D & $\mathrm{N}$ & N/A \\
\hline $\begin{array}{l}\text { Is European end-of-life vehicle legislation living up to } \\
\text { expectations? Assessing the impact of the ELV Directive } \\
\text { on 'green' innovation and vehicle recovery (Gerrard and } \\
\text { Kandlikar, 2007). }\end{array}$ & N.D & N.D & N.D & $\mathrm{N}$ & $\mathrm{N} / \mathrm{A}$ \\
\hline $\begin{array}{l}\text { Making sense out of industrial ecology: A framework for } \\
\text { analysis and action (Cohen-Rosenthal, 2004). }\end{array}$ & $\mathrm{N}$ & N.D & N.D & Y & Y \\
\hline $\begin{array}{l}\text { Reducing waste: Repair, recondition, remanufacture or } \\
\text { recycle? (King et al., 2006). }\end{array}$ & Y & Y & N.D & Y & $\mathrm{N}$ \\
\hline $\begin{array}{l}\text { Remanufacturing of turbine blades by laser direct } \\
\text { deposition with its energy and environmental impact } \\
\text { analysis (Wilson et al., 2014). }\end{array}$ & Y & N.D & N.D & Y & Y \\
\hline $\begin{array}{l}\text { Reuse of second hand TVs exported from Japan to the } \\
\text { Philippines (Yoshida and Terazono, 2010). }\end{array}$ & Y & Y & Y & N.D & Y \\
\hline $\begin{array}{l}\text { Sustainable life cycle engineering of an integrated } \\
\text { desktop PC; a small to medium enterprise perspective } \\
\text { (Fitzpatrick et al., 2014). }\end{array}$ & N.D & N.D & Y & N.D & $\mathrm{N} / \mathrm{A}$ \\
\hline $\begin{array}{l}\text { Towards cleaner production: A roadmap for predicting } \\
\text { product end-of-life costs at early design concept (Cheung } \\
\text { et al., 2015). }\end{array}$ & $Y$ & Y & Y & $Y$ & $Y$ \\
\hline $\begin{array}{l}\text { Waste management life cycle assessment: The case of a } \\
\text { reciprocating air compressor in Brazil (Zanghelini et al., } \\
\text { 2014). }\end{array}$ & N.D & N.D & N.D & Y & $\mathrm{N} / \mathrm{A}$ \\
\hline
\end{tabular}

R1: repair; R2: recondition; R3: refurbish; R4: remanufacture; RU: reuse; N.D: not defined, described or discussed or the information is insufficient to conclude; N/A: not applicable. [AQ: 10]

products'. The analysis confirms that 10 out of 17 (59\%) of the articles lack clarity between identified reuse options (refer to Table 2). Each article was also analysed to check whether the definition and/or description of each of the identified 'reuse' options was considered to be part of a 'reuse' option or not. It is observed that very few articles describe or discuss all 'reuse' options and very few actually define 'reuse' options, although some cite original definitions from other sources. The decision as to whether the authors of this article consider a particular measure to be a 'reuse' option is based on the definition and/or description of that measure and/or the description of that measure vis-à-vis other measures. Figure 3 illustrates the outcome graphically. It is evident that while $34 \%$ of articles consider either 'repair' or 'recondition' or 'refurbish' or 'remanufacture' as a 'reuse' option, 23\% do not and
$43 \%$ have either not defined nor sufficiently described or discussed at a sufficient level to conclude whether or not the option can be considered as a 'reuse' option.

Table 3 uses selected examples to indicate that the defined or described option (measure) is not considered as part of 'reuse' option and/or existence of lack of clarity between different options.

\section{Discussions}

\section{Hierarchy of reuse options}

Ijomah et al. (2005) proposes a 'hierarchy of secondary market production processes' that puts 'repair', 'refurbish' and 'remanufacture' in increasing order of (i) work content, (ii) performance 
Inclusion/Exclusion from Reuse

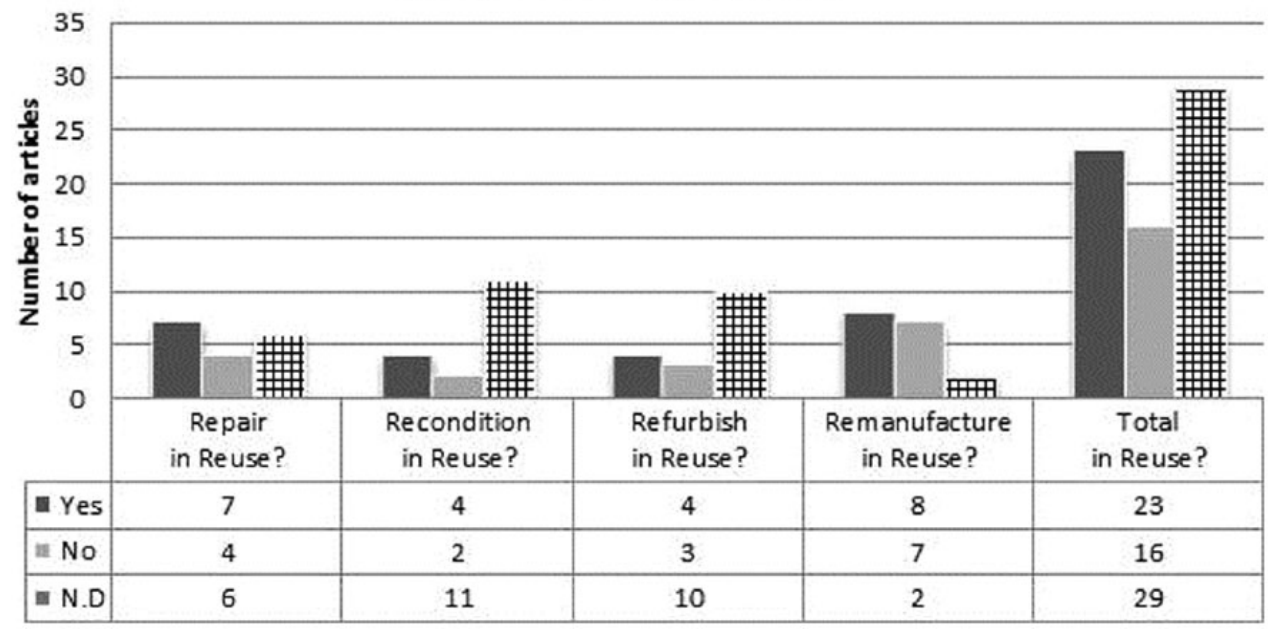

Figure 3. Whether the article considers repairs, recondition, refurbish and/or remanufacture as 'reuse' option. N.D: not defined, described or discussed or the information is insufficient to conclude.

Table 3. Examples of lack of clarity and/or overlap between different options.

\begin{tabular}{ll}
\hline Reference & Description \\
\hline Ziout et al. (2014) & The authors identify 'resale', 'maintenance', 'repair', 'replacement', 'refurbishing' and \\
'remanufacturing' as 'reuse' options and observe that clear cut definitions and distinctions \\
between these options do not exist in literature or practice. \\
This article is on 'remanufacturing' of dies and moulds. The authors mostly use the term \\
'repair' for 'remanufacturing' and also use terms such as 'refurbishing' and 'reconditioning' \\
to describe the same individual stage of the 'remanufacturing' process without clarifying the \\
commonality or difference between these terms.
\end{tabular}

Gehin et al. (2008) This article only considers direct 'reuse' (without further operation except resale) as a 'reuse' option. Also, the 3R strategy of reuse, remanufacture and recycle for EOL products clearly indicate that 'remanufacture' is not considered as part of 'reuse'.

Go et al. (2011)

'Remanufacturing' is not considered as a 'reuse' option. This is evident from the statement 'apart from recycling, there are other EOL options including reuse and remanufacturing'. Also, the flowchart for 'physical product life cycle' describes 'reuse' of parts for 'remanufacturing' as 'recycling' of parts (recycling is getting back EOL objects that cannot be reused, to raw material constituent stage).

Pigosso et al. (2010) 'Reuse' is restricted to 'resale and reuse' of used objects. Also, the flow chart of 'typical material product life cycle' shows 'remanufacturing' as a distinct option to 'reuse'. Overlap between 'reuse' and 'recycling' is evident from the statement 'recycling is the process of collecting used products, components, ... to disassemble, ..., and process them as recycled products, components, and/or materials'. Lack of clarity between 'repair' and 'refurbish' is evident from 'The main recovery strategies.... are direct reuse, reuse after small repairs lalso known as refurbishment)'.

Cohen-Rosenthal (2004) The 'hierarchy of material use and reuse' identifies 'autogenesis', 'reuse', 'repair' and 'remanufacture' as options of 'extended use'. This indicates that 'repair' and 'remanufacture' are considered distinct to 'reuse'. But while describing 'remanufacturing', they observe that 'remanufacturing is a term increasingly in favour for a process that is a subset of reuse'. Surely there is lack of clarity whether 'remanufacturing' is a 'reuse' option or not.

Wilson et al. (2014) The article describes 'repair' or 'reconditioning' or 'refurbishing' of a worn out turbine blade by a third part (not OEM) as 'remanufacturing'. The article mostly uses the term 'repair' to describe 'remanufacturing'. Also, 'reuse' does not appear in the article even once. 'Laser direct deposition lends itself to "repair" non-repairable components ... repairing defective voids...'. Another inconsistency is - owing to lack of access to OEM specifications (intellectual property), third party cannot offer 'as new warranty'.

EOL: end-of-life; OEM: . [AQ: 11]

and (iii) warranty. While discussing the best closed loop option, King et al. (2006) cites the second law of thermodynamics and observes that 'repairing', 'reconditioning' and 'remanufacturing' consumes energy in increasing order. Increased work content and energy consumption is related to increased cost. With the addition of inputs on energy and cost, a 'hierarchy of reuse options' is 


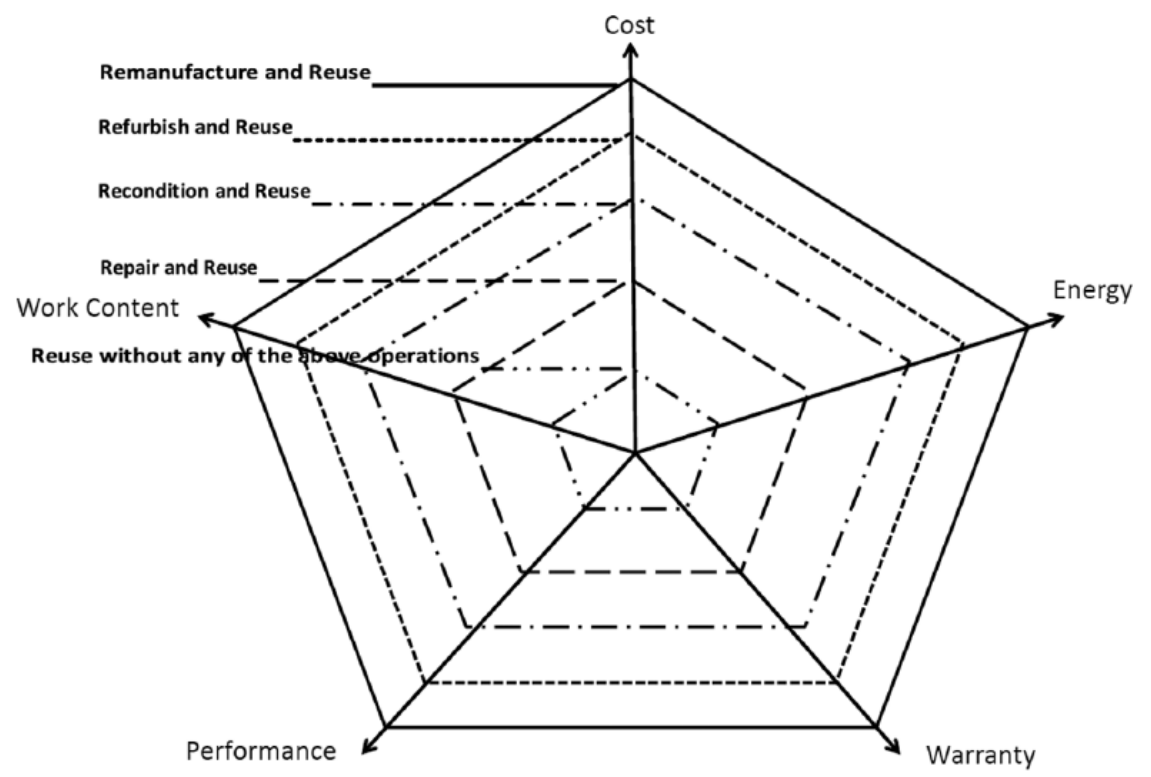

Figure 4. Hierarchy of reuse options.

being proposed (Figure 4) as an extension of the 'hierarchy of secondary market production processes' developed by (Ijomah et al., 2005). The proposed 'hierarchy of reuse options' is based on five parameters, namely (i) work content, (ii) performance (life), (iii) warranty, (iv) energy requirement and (v) cost. The hierarchy is not absolute, but it only indicates relative positions of different 'reuse' options on these five parameters. Further research is required to establish the 'level of upgrade' (new, updated or latest features) that is offered by different 'reuse' options. This research may be conducted either through a systematic review of literature within the environmental sciences and/or electro-mechanical engineering discipline or by studying international standards in the electro-mechanical sector or by studying prevailing best practices in the electro-mechanical products/ goods manufacturing sector. Once the relative position of the 'level of upgrade' between different reuse options (repair, recondition, refurbish and remanufacture) is established/confirmed through such research, the 'level of upgrade' could form the sixth parameter of the 'hierarchy of reuse options'.

The five main levels of 'reuse' described in Figure 1 are included in the proposed 'hierarchy of reuse options'. These are (i) reuse without any treatment (direct reuse), (ii) repair and reuse, (iii) recondition and reuse, (iii) refurbish and reuse and (v) remanufacture and reuse. While the hierarchy between 'repair', 'refurbish' and 'remanufacture' have already been validated and established by Ijomah et al. (2005), the authors propose to include and place 'refurbish' above 'recondition' in the proposed hierarchy. This is because 'reconditioning' involves bringing an object to an acceptable working condition. This is generally inferior to that of original model without the latest functionality or aesthetic styling of a new product (King et al., 2006). On the other hand 'refurbishing' has an element of upgrade to it as established by Ziout et al. (2014), who observes that the main objective of 'refurbishing' is to improve functionality and appearance of a product by adding new items or replacing obsolete items with better performing items. However, further research may be required to validate and establish the difference and hierarchy between 'recondition' and 'refurbish'. This research may be conducted either through a systematic review of literature within the environmental sciences and/or electro-mechanical engineering discipline or by studying international standards in the electromechanical sector or by studying prevailing best practices in the electro-mechanical products/goods manufacturing sector. Once the relative position of 'refurbish' over 'recondition' is established/confirmed through such research, the 'hierarchy of reuse options' could form the basis of techno-commercial offerings, such as price and warranty/guarantee, to the customers and for governments to offer incentives, such as corporate tax relief and VAT exemption, to the businesses that offer repaired or reconditioned or refurbished or remanufactured products. Such incentives can act as an enabler/catalyst of a 'closed loop circular economy'.

\section{Remanufacturing debate}

'Remanufacturing and reuse' has great potential in recovering reusable resources from end-of-life (EOL) products. Two things that matter most to consumers are 'fitness for use' and manufacturer's 'warranty' of the final product. Both can be achieved by 'remanufacturing'. Lavery et al. (2013) identifies one of the key barriers to remanufacturing as lack of clear legal definition for remanufacturing. As a result, reconditioned, refurbished products are wrongly marketed as remanufactured products. The first report on 'remanufacturing' by the All-Party Parliamentary Sustainable Resource Group (APSRG) observes that a 'key barrier to the uptake of successful remanufacturing is the return of end-of-life products (core) from the consumer to the remanufacturer'. A recent inquiry by APSRG and the All-Party Parliamentary 
Manufacturing Group (APMG) on 'Remanufacturing - Resource Security and Opportunities for Growth' posed the following key questions in addition to others on 'remanufacturing' (PolicyConnect, 2014).

1. What can manufacturers do to ensure they get their products back at the end of their first life?

2. Are there any Government initiatives needed to drive this?

3. What regulations or incentives are still needed by Government to encourage remanufacturing?

While manufacturing constitutes about $10 \%$ of the UK economy, Lavery et al. (2013) observe that less than $2 \%$ of non-perishable/ non-consumable products are remanufactured. Their study quantifies the benefits of circular use of resources that include remanufacturing, to the UK economy. Economic benefits include 12\% increase in profits equivalent to $£ 10$ billion per annum to UK manufacturers, social benefits include $12 \%$ increase in manufacturing jobs amounting to 314,000 new jobs and environmental benefits include $4.5 \%$ reduction in UK's greenhouse gas emissions equivalent to 27 million tonnes [AQ: 3] of $\mathrm{CO}_{2}$ per annum. They have also identified a number of barriers to the adoption of circular resource use, especially remanufacturing. Barriers include lack of experience and influence of senior leadership, lack of awareness about the benefits of remanufacturing, confusion and misunderstanding over the term 'remanufacturing', product design, recovery infrastructure, customer perception and legal and regulatory constraints. The regulatory impediments to remanufacturing have been identified as 'banning of remanufactured components in new goods', the UK Sales and Goods Act (SoGA) that discourages retailing of used goods, classification of remanufactured products as used, definitions of waste that hinder transport and trade of products for remanufacturing, etc.

Similarly, APSRG and APMG (2014) has identified a number of barriers to remanufacturing. The key objective of this inquiry was to assess the position of the UK in the global remanufacturing sphere, identify industries where it is prevalent and industries that may need support. The inquiry also identified a number of drivers and hurdles to remanufacturing in the UK. Identified drivers include reduced cost of input, reduced carbon emission and reduced water and energy use that leads to resource security and resilience in a volatile world. Identified barriers include lack of a global legal definition of remanufacturing, intellectual property conflicts, negative regulatory frameworks, shortage of skills and engrained linear business models. The authors of this report observe that parts and products due for remanufacturing should not be classified as waste, unlike the focus of existing regulatory framework and directives that classify EOL parts and products as waste. One of its recommendations calls for amendment of government guidance on the legal definition of waste to distinguish a product due for remanufacturing to be exempt from products considered as waste. These barriers do not apply to leasing, renting or servitisation models. But where these models cannot be applied and there is a techno-economic or environmental potential for 'remanufacturing and reuse' of products, certain regulatory changes are required.

While Lavery et al. (2013) confirms 'banning of remanufactured components in new goods' as a regulatory barrier to remanufacturing, and APSRG and APMG (2014) recommends amendment of the legal definition of waste to exclude a product due for remanufacturing, can the adoption of the following initiatives 'incentivise' OEMs to be directly involved in the business of 'remanufacturing' of products manufactured by them?

1. Revision of the current legal definition of a part or a component to include part or a component recovered from EOL products as long as they satisfy the OEM specifications and standards of a new part or a component. Recovered parts or components can meet OEM specifications, with or without 'repairing' and/or 'reconditioning' and/or 'refurbishing' of each of the recovered part or a component.

2. Merging of 'remanufacturing' with 'manufacturing' operations. Recovered parts or components can be legally allowed to be used in the manufacturing of not just 'remanufactured' products, but also 'new' products, as long as they meet OEM specifications and standards of new parts or components.

3. Enshrine the 'extended producer responsibility' into manufacturing laws that will place the primary responsibility of circulating EOL products into the 'reuse' loop for a longer time, on the OEMs.

Organization for Economic Cooperation and Development (2001) defines extended producer responsibility (EPR) as a 'policy approach under which producers accept significant responsibility - financial and/or physical for the disposal of post-consumer products'. It aims to 'provide incentives to prevent waste at the source; promote design for the environment and support the achievement of public recycling and materials management goals'. According to Zaman (2014), EPR is an important strategy for making industries accept responsibility for their end of line (EOL) [AQ: 4]products and one of the important elements in 'zero waste management'. Massarutto (2014) observes that EPR enlarges the focus from an 'end-of-pipe management of waste' to 'resource efficiency', with a substantial boost to waste prevention and recycling. Considering the severity of resource scarcity, regulations will continue to play an important role in improving circularity. Hence the suggestion to enshrine EPR into manufacturing laws of every country that places the primary responsibility of circulating EOL products manufactured/produced by each respective manufacturer/producer. Legislation of EPR into laws related to operation of manufacturing units would force them to rethink their existing business models and consider circular business models such as 'leasing', 'renting' and 'servitisation' that ensure 'recovery and reuse' of parts/components/products by 'repairing'; 'reconditioning', 'refurbishing' or 'remanufacturing'. Circular business models not only offer environmental benefits but also socio-economic benefits. 


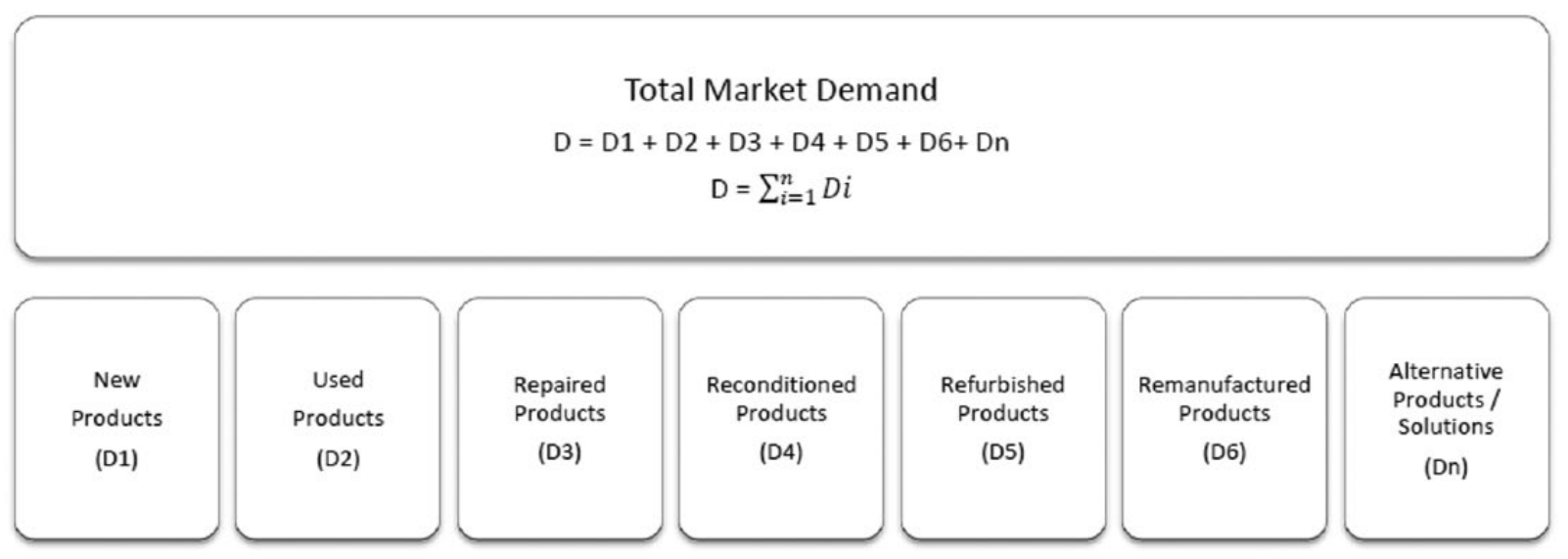

Figure 5. Market demand for various categories of products at a particular point in time.

One of the main fears to 'remanufacturing' cited by OEMs is the 'cannibalisation' of their market share (Atasu et al., 2008). The fear is that 'remanufactured' products eat into the market share of new products (cannibalisation). A counter argument to the fear of cannibalisation as envisaged by the authors of this article, is that if OEMs themselves get involved in the business of 'remanufacturing' their own products, then the fear of 'cannibalisation' becomes invalid for the following reasons.

1. At any point in time, total market demand (D) is fixed (Figure 5). The decision on whether to buy a 'new' or a 'used' or a 'repaired' or a 'reconditioned' or a 'refurbished' or a 'remanufactured' or any 'alternative product or solution' will depend on the 'perceived value' of that product or solution and not just on the 'valuation' or 'sales price' of the product or solution.

2. Profit margins of 'remanufactured' products are either comparable or more than new products. It is considered as a low cost alternative to a 'new' product (Atasu et al., 2008).

\section{Closed loop resource flow models}

The three material (resource) flow models of biological and industrial ecosystems namely, Type I, Type II and Type III envisaged by Graedel and Allenby (1995) (Figure 6), [AQ: 5]are fundamental to understanding how sustainability can be achieved. In the context of an industrial ecosystem, the Type I system that is ecologically considered as an 'open system' or a 'linear system' of resource flows is evidently detrimental to sustainability. This is because it is a unidirectional system that is made up of extraction, manufacturing/production, use and disposal (extract-makeuse-dispose). Although a Type II system is more efficient than Type I, it is also not sustainable over a long run. [AQ: 6]This is because, despite an element of closing the loop, there is still an element of waste that not only depletes finite resources but also pollutes or degrades the ecosystem. Graedel and Allenby (1995) observe that even the Type II system is 'running down'; requires 'landfills' that tend to leak; are expensive to maintain; mix materials that make it difficult to recover and reuse and therefore not sustainable. On the other hand, they describe Type III as the 'ideal ecosystem' that has only 'energy' on the input and no 'waste' on the output side. In the Type III system envisaged by them, 'waste' of one component of the ecosystem acts as a 'resource' to another on a continuous basis.

Consumption of natural resources exceeds the capacity of the planet to supply these resources and to sustain its consequences. Therefore, the closed-loop systems represented by the Type II or ideally by the Type III resource flow model are considered inevitable if sustainable development is to be achieved (Rashid et al., 2013). While the Type I system/model of resource flows is evidently unsustainable, Nasr and Thurston (2006) conceptualised and elaborated the Type II resource flow model into its individual elements. But their model does not consider 'remanufacture' as one of the 'reuse' options and also does not include other 'reuse' options, such as 'repair', 'recondition' and 'refurbish' in it. Rashid et al. (2013) identified certain shortcomings in the Type II resource flow model developed by Nasr and Thurston (2006) and proposed a modified concept of Type II closed-loop product system, which they named a Resource Conservative Manufacturing (ResCoM) Product System. But this model also does not consider all 'reuse' options, and therefore the authors of this article propose an alternative Type II resource flow model, which is described in the next section.

\section{Alternative Type I/ model of resource flows}

Graedel and Allenby (2010) argue that the current levels of population, urbanisation patterns, economies and cultures are linked to how we use, process, dispose of and recover materials and energies. As indicated earlier, both the Type II closed-loop product system (material flows) conceptualised by Nasr and Thurston (2006) and the modified version of ResCoM proposed by Rashid et al. (2013) ignore other options of 'reuse'. In order to overcome these shortcomings, an alternative version of the Type II model named the 'alternative Type II model of resource flows' is being proposed (Figure 7). Different 'reuse' options that are captured under this model are included from the ' $5 \mathrm{Rs}$ of resource effectiveness' (Figure 1). 


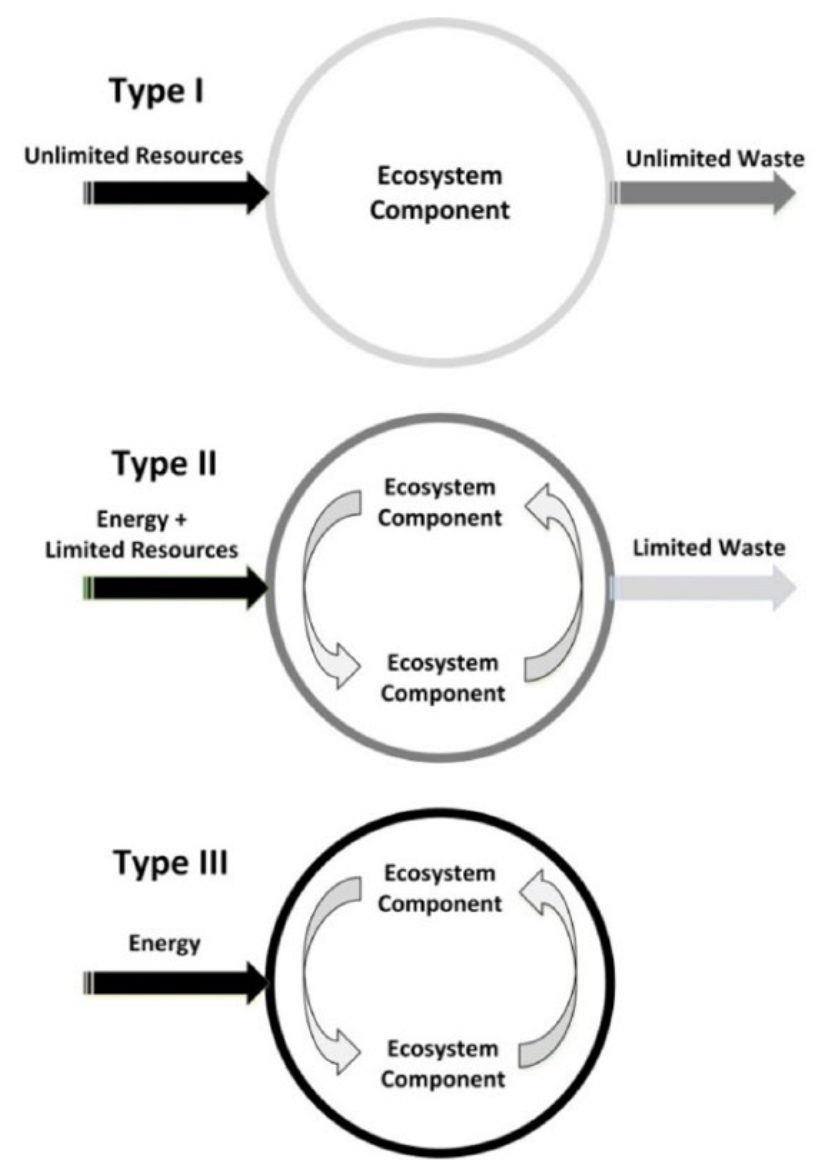

Figure 6. Resource flow models (by Graedel and Allenby, 1995). [AQ: 12]

\section{Introduction of Type II/2 model of resource flows}

As per Rashid et al. (2013), the contemporary closed-loop product system that represents the Type II resource flow model is intended to fulfil three key demands of sustainability.

1. Minimisation of material and energy consumption.

2. Maximisation of expended resources.

3. Minimisation of adverse environmental impacts.

Graedel and Allenby (1995) consider Type II system as 'running down' and therefore not sustainable. Without an emphasis on the type of scarce natural resources that are used on the input side (renewable or non-renewable; hazardous or environmentally benign), even the 'alternative Type II model of resource flows' suggested in this article (Figure 7) will not be able to achieve sustainability. The Type III is an ideal model, but practically difficult to achieve. None of the models emphasise on the type of resources to be used, such as renewable or non-renewable, hazardous or environmentally benign. Hence there is a need for a practically achievable but sustainable resource flow model that falls between the Type II and Type III. This could be defined as 'Type II/2 model of resource flows' (Figure 8). The main difference between the Type II and Type II/2 models is the 'replacement' of 'non-renewable' and 'hazardous' natural resources with 'renewable' and 'environmentally benign' natural resources at the input that would result in an 'environmentally benign' output (adopted from first $\mathrm{R}$ of the $5 \mathrm{Rs}$ of resource effectiveness in Figure 1).

'Renewable resources' are generally considered to be more environmentally friendly than 'non-renewable resources'. But a life cycle analysis would be necessary to determine whether the renewable resource is better than the non-renewable resource being replaced. For example, cotton fibre is considered as environmentally friendly (benign) as compared with polyester fabric. But cotton, which is the main resource for the production of cotton fabric, could be cultivated using one of the following two routes:

(a) use of chemical fertilisers, chemical pesticides, underground water and tractors/mechanised equipment consuming fossil fuel based energy; or

(b) use of organic fertilisers, organic pesticides, harvested rain water and animal/ human efforts and/or mechanised equipment based on solar energy.

Without doubt, in the context of the 'cotton cultivation' process, route (b) is environmentally friendly (benign) as compared with route (a). It is not only better for the environment, but also for human health. This is because chemicals, fossil fuel and underground water has been 'replaced' by environmentally benign and renewable resources that ensure an environmentally benign product, organic cotton on the output side. The Type II/2 model of resource flows suggest that if 'environmentally benign' and 'renewable resource' are used on the consumption side, then the products, by-products and 'waste' generated on the output side are most likely to be 'environmentally friendly (benign)'.

\section{Conclusion and future work}

The main objective of this research was to understand whether inconsistencies and/or discrepancies exist between the descriptions/definitions of identified 'reuse' options. Analysis of the identified literature within the 'environmental science discipline' related to 'mechanical and electromechanical products' undoubtedly confirms that in the majority, 59\% of cases, disagreement does exist. Acknowledgement and/or confirmation of existence of a problem (in this case, disagreement or non-standard definitions), is the first step to its resolution. Further research may be conducted by widening the scope of the literature search to the 'engineering' and 'manufacturing' disciplines. Confirmation of disagreement on each of the 'reuse options' within the engineering and manufacturing disciplines could form the first step for working towards standardisation of definitions of each of these 'reuse options'.

With only three ISO and BSI standards for 'remanufacturing', as against 122 for 'repairs' and none for 'reconditioning' or 'refurbishing', there is a gap and the need for establishing appropriate standards for all the 'reuse' options is clear. However, before establishing standards for various 'reuse' options, it will be necessary to standardise the definitions. To do this, it may also 


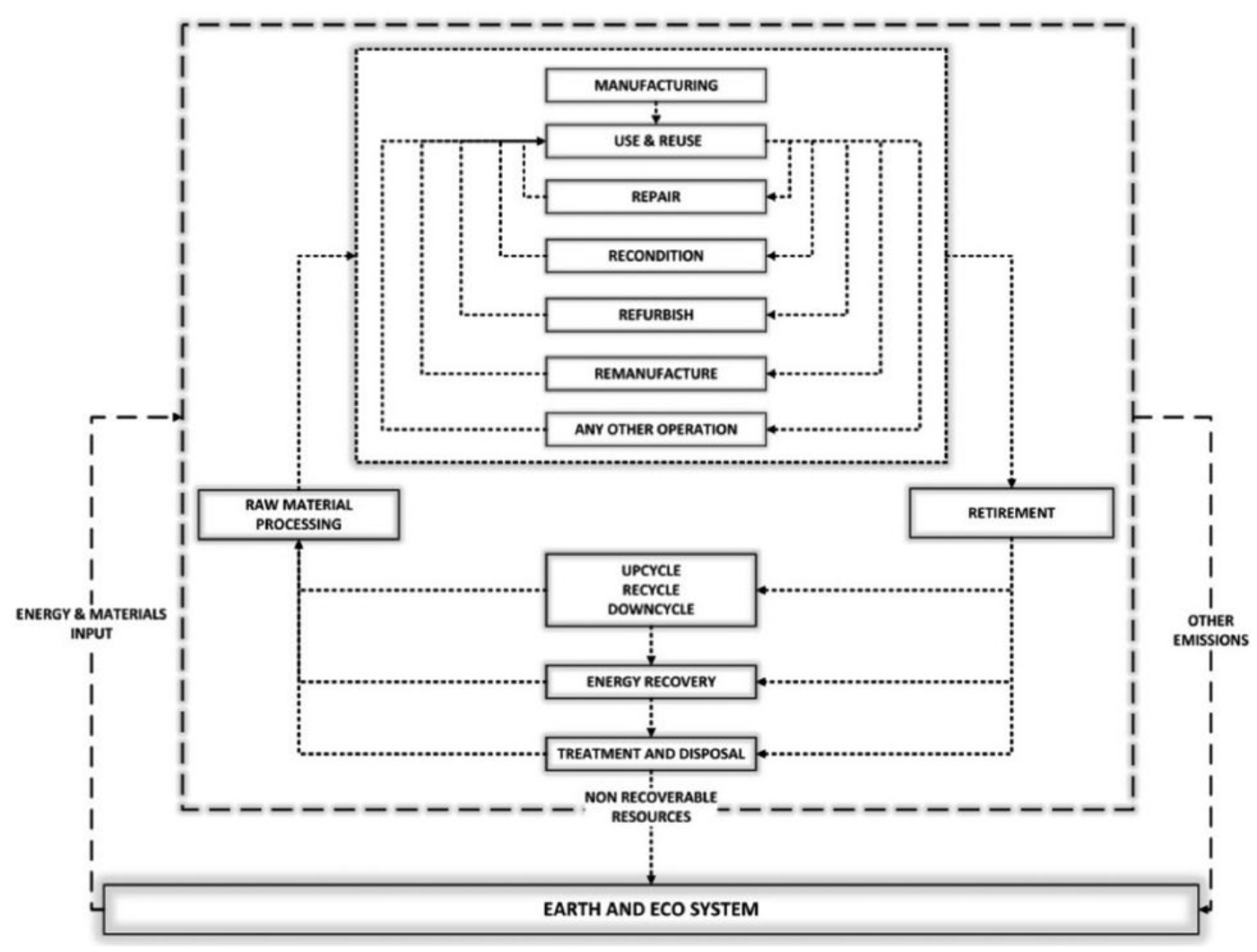

Figure 7. Alternative Type II model of resource flows.

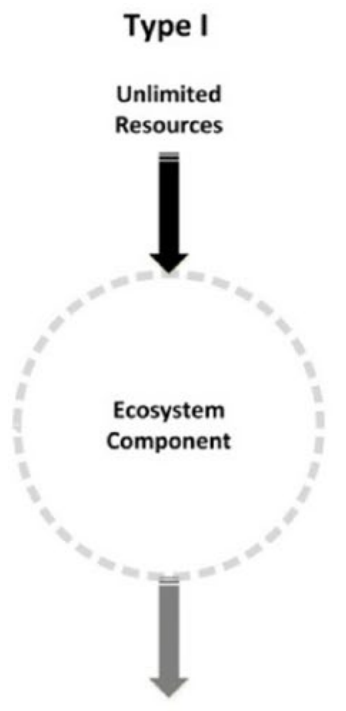

Unlimited Waste

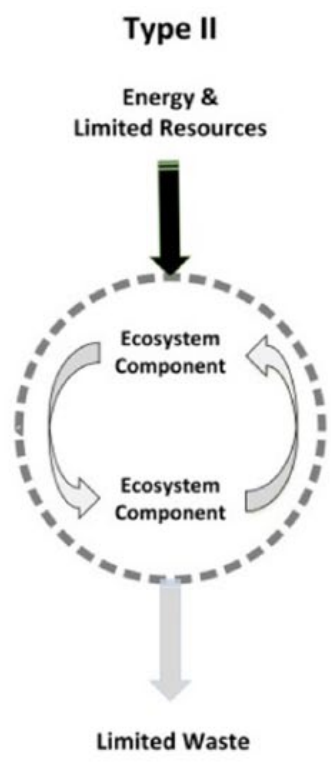

Figure 8. Introduction of Type II/2 model of resource flows.

be necessary to understand which of the 'reuse' options could be applied at product, assembly (module), sub-assembly and component level. In order to develop standard definitions for each of the reuse options, it may be necessary to extend the scope of this research to studying the 'definitions' of identified 'reuse options' to environment dictionaries, business dictionaries, guideline and policy documents of regulatory bodies and environment agencies (The US Environment Protection Agency (EPA), the European Environment Agency (EEA), Department of Environment and
Type II/2

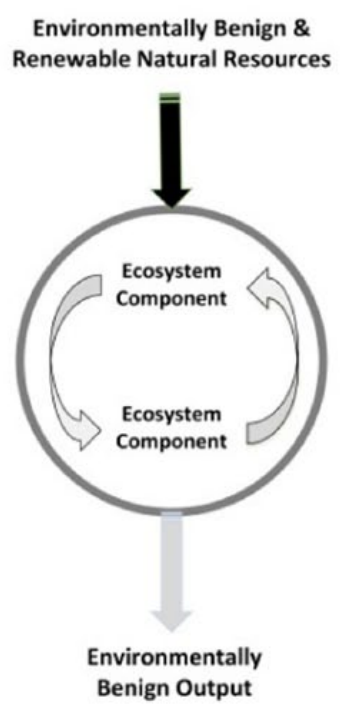

Type III

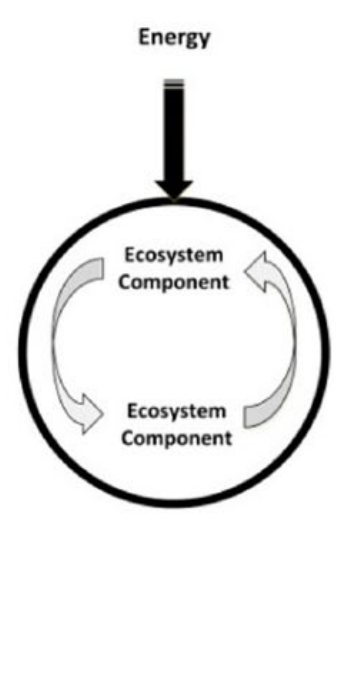

Rural Affairs (DEFRA), etc.). Research may also include guidelines and policy documents of organisations, such as the United Nations Environment Programme (UNEP), the Organization for Economic Cooperation and Development (OECD) and Waste and Resources Action Plan (WRAP).

Standardised definitions of each of the reuse options could enable businesses to justify techno-commercial offerings, such as price and warranty/guarantee, to the customers. They could be of help to governments in offering incentives, such as corporate tax 
relief and VAT exemption, to the businesses that offer repaired or reconditioned or refurbished or remanufactured products. All these measures in turn would act as an enabler of a 'closed loop circular economy'.

Further research may be required to confirm the differences and hierarchy between 'recondition' and 'refurbish'. Further research may also be carried out in comparing the 'definitions' of various reuse options with a view to arriving at a universally acceptable definition of each option. This could include study of environment and business dictionaries, policy/regulatory documents of organisations such as UNEP, US EPA, EEA, DEFRA and WRAP.

\section{Acknowledgements}

Mangesh Gharfalkar wishes to acknowledge the support offered by Teesside University through a $\mathrm{PhD}$ studentship to enable this research. Underlying research materials related to this article can be obtained by contacting the corresponding author via email m.gharfalkar@tees.ac.uk

\section{Declaration of conflicting interests}

The authors declared no potential conflicts of interest with respect to the research, authorship, and/or publication of this article.

\section{Funding}

The authors received no financial support for the research, authorship, and/or publication of this article.

\section{References}

Amelia L, Wahab DA, Che Haron CH, et al. (2009) Initiating automotive component reuse in Malaysia. Journal of Cleaner Production 17: 1572-1579.

All-Party Parliamentary Sustainable Resource Group and All-Party Parliamentary Manufacturing Group (2014) Triple Win: The Social, Economic and Environmental Case for Remanufacturing. London.

Atasu A, Sarvary M and Wassenhove LNV (2008) Remanufacturing as a marketing strategy. Management Science 54: 1731-1746.

Butti L (2012) Birth and death of waste. Waste Management 32: 1621-1622.

Chen C, Wang Y, Ou H, et al. (2014) A review on remanufacture of dies and moulds. Journal of Cleaner Production 64: 13-23.

Cheung WM, Marsh R, Griffin PW, et al. (2015) Towards cleaner production: A roadmap for predicting product end-of-life costs at early design concept. Journal of Cleaner Production 87: 431-441.

Cohen-Rosenthal E (2004) Making sense out of industrial ecology: A framework for analysis and action. Journal of Cleaner Production 12: 1111-1123.

Directive 2008. Directive 2008/98/EC of The European Parliament and of The Council on Waste and Repealing Certain Directives. Official Journal of the European Union.

Fitzpatrick C, Hickey S, Schischke K, et al. (2014) Sustainable life cycle engineering of an integrated desktop PC; a small to medium enterprise perspective. Journal of Cleaner Production 74: 155-160.

Gaba JM (1989) Solid waste and recycled materials under RCRA: Separating chaff from wheat. Ecology LQ 16: 623-666.

Gaussin M, Hu G, Abolghasem S, et al. (2013) Assessing the environmental footprint of manufactured products: A survey of current literature. International Journal of Production Economics 146: 515-523.

Gehin A, Zwolinski P and Brissaud D (2008) A tool to implement sustainable end-of-life strategies in the product development phase. Journal of Cleaner Production 16: 566-576.

Gerrard J and Kandlikar M (2007) Is European end-of-life vehicle legislation living up to expectations? Assessing the impact of the ELV Directive on 'green' innovation and vehicle recovery. Journal of Cleaner Production 15: 17-27.

Gharfalkar M, Court R, Campbell C, et al. (2015) Analysis of waste hierarchy in the European Waste Directive 2008/98/EC. Waste Management 39: 305-313.
Go TF, Wahab DA, Rahman MNA, et al. (2011) Disassemblability of end-oflife vehicle: A critical review of evaluation methods. Journal of Cleaner Production 19: 1536-1546.

Graedel TE and Allenby BR (1995) Industrial Ecology. Engelwood Cliffs, NJ: Prentice Hall.

Graedel TE and Allenby BR (2010)) Industrial Ecology and Sustainable Engineering. Boston, MA: Pearson.

Hatcher GD, Ijomah WL and Windmill JFC (2011) Design for remanufacture: A literature review and future research needs. Journal of Cleaner Production 19: 2004-2014.

Hatcher GD, Ijomah WL and Windmill JFC (2014) A network model to assist 'design for remanufacture' integration into the design process. Journal of Cleaner Production 64: 10.

House of Lords (2014) House of Lords - Science and Technology Select Committee: Waste or Resource? Stimulating a Bioeconomy-HL 141. London: The Stationary Office, 141, 5-68.

Ijomah WL, Hammond GP, Childe SJ, et al. (2005) A robust description and tool for remanufacturing: A resource and energy recovery strategy. Environmentally conscious design and inverse manufacturing, 2005. In: Eco Design 2005, 4th international symposium, 12-14 December 2005, pp.472-479.

King AM, Burgess SC, Ijomah W, et al. (2006) Reducing waste: Repair, recondition, remanufacture or recycle? Sustainable Development 14: 257-267.

Lavery G, Pennell N, Brown S, et al. (2013) The Next Manufacturing Revolution: Non-Labour Resource Productivity and its Potential for UK Manufacturing. [AQ: 7]

Mangun D and Thurston DJ (2002) Incorporating component reuse, remanufacture, and recycle into product portfolio design. IEEE Transactions on Engineering Management 49: 479-490.

Massarutto A (2014) The long and winding road to resource efficiency An interdisciplinary perspective on extended producer responsibility. Resources, Conservation and Recycling 85: 11-21. [AQ: 8]

Nasr N and Thurston M (2006) Remanufacturing: A key enabler to sustainable product systems. In: 13th CIRP international conference on life cycle engineering, 2006. [AQ: 9]

Organization for Economic Cooperation and Development (2001) Extended Producer Responsibility: A Guidance Manual for Governments. Paris: OECD Publishing.

Park JY and Chertow MR (2014) Establishing and testing the "reuse potential" indicator for managing wastes as resources. Journal of Environmental Management 137: 45-53.

Pigosso DCA, Zanette ET, Filho AG, et al. (2010) Ecodesign methods focused on remanufacturing. Journal of Cleaner Production 18: 21-31.

Policy-Connect (2014) Inquiry: Remanufacturing - Resource Security and Opportunities for Growth. Policy Connect.

Rashid A, Asif FMA, Krajnik P, et al. (2013) Resource conservative manufacturing: An essential change in business and technology paradigm for sustainable manufacturing. Journal of Cleaner Production 57: 166-177.

Seitz MA and Wells PE (2006) Challenging the implementation of corporate sustainability: The case of automotive engine remanufacturing. Business Process Management Journal 12: 822-836.

The Remanufacturing Institute (TRI) (2014) What remanufacturing is not? [Online]. The Remanufacturing Institute (TRI). Available at: http://www. reman.org (accessed 20 April 2014).

Tromans S (2001) EC Waste law-A complete mess? Journal of Environmental Law 13: 133-156.

Wilson JM, Piya C, Shin YC, et al. (2014) Remanufacturing of turbine blades by laser direct deposition with its energy and environmental impact analysis. Journal of Cleaner Production 80: 170-178.

Yoshida A and Terazono A (2010) Reuse of secondhand TVs exported from Japan to the Philippines. Waste Management 30: 1063-1072.

Zaman AU (2014) Measuring waste management performance using the 'Zero Waste Index': The case of Adelaide, Australia. Journal of Cleaner Production 66: 407-419.

Zanghelini GM, Cherubini E, Orsi P, et al. (2014) Waste management life cycle assessment: The case of a reciprocating air compressor in Brazil. Journal of Cleaner Production 70: 164-174.

Ziout A, Azab A and Atwan M (2014) A holistic approach for decision on selection of end-of-life products recovery options. Journal of Cleaner Production 65: 497-516. 